\title{
O NOVO CÓDIGO DE PROCESSO CIVIL E OS PRECEDENTES VINCULANTES: REFLEXÕES EM BUSCA DE UMA APLICAÇÃO ADEQUADA
}

\section{THE NEW CIVIL PROCEDURE CODE AND THE BINDING PRECEDENTS: REFLECTIONS IN SEARCH OF AN ADEQUATE APPLICATION}

\author{
Ellen Carina Mattias Sartori ${ }^{1}$ \\ Caroline Schneider ${ }^{2}$
}

\section{RESUMO}

O novo Código de Processo Civil reverenciou os chamados "precedentes vinculantes" com o fim de resguardar os princípios constitucionais da isonomia e da segurança jurídica, bem como a unidade da jurisdição. A ausência de uma cultura jurídica com base nos precedentes no Brasil, no entanto, faz surgir inúmeras imprecisões que ameaçam os objetivos do novo Código. O artigo, assim, reflete sobre algumas técnicas de aplicação e flexibilização dos precedentes, desenvolvidas ao longo dos anos nos países que adotam o common law, que serão essenciais para que o novo diploma atinja seus desígnios garantindo uma atividade jurisdicional célere, eficaz, justa e igualitária.

Palavras-chave: Novo Código de Processo Civil; Precedentes; Stare Decisis; Ratio Decidendi; Segurança Jurídica.

\begin{abstract}
The new Civil Procedure Code revered the binding precedents as a way of shield the constitutionals principles of isonomy and legal security, as well as jurisdiction unit. The absence of a juridical culture based on precedents in Brazil, however, brings out several imprecisions that put on threat the objectives of the new Code. The article, thus, reflects about some application and flexibility precedent's techniques, developed over the years in the countries that adopted the common law, that would be essential for the new code to reach the intention to establish a fast, effective, fair and equal jurisdictional activity.
\end{abstract}

Keywords: New Civil Procedure Code; Precedents; Stare Decisis; Ratio Decidendi; Legal Security.

\footnotetext{
${ }^{1}$ Mestre em Direito pela Instituição Toledo de Ensino - ITE, São Paulo (Brasil) .. Professora de Direito Civil da Instituição Toledo de Ensino (ITE). Advogada. E-mail: ecsartori@uol.com.br

${ }^{2}$ Mestre em Direito pela Instituição Toledo de Ensino - ITE, São Paulo (Brasil). Professora de Processo Civil em vários cursos de Pós-Graduação. Coordenadora do Núcleo ESA da OAB-Ourinhos. Advogada e Analista do Seguro Social com formação em Direito. E-mail: krolschneider@hotmail.com
} 


\section{INTRODUÇÃO}

O novo Código de Processo Civil foi elaborado com o desígnio de atender aos anseios da Constituição Federal de 1988, principalmente em relação à celeridade e à efetividade processual, tendo como meta inafastável um resultado justo. De tal modo, o novo Código deixa patente que a lei processual e a atividade jurisdicional em si submetem-se às normas e aos valores constitucionais, os quais lhe servem de fonte e legitimam o seu exercício.

Logo em seu primeiro Livro, o novo diploma já elenca as garantias constitucionais que balizam o sistema processual brasileiro, que passam a retratar a principiologia do novo Código de Processo Civil: o acesso à justiça, o devido processo legal, a duração razoável do processo, o contraditório, a dignidade da pessoa humana, a eficiência, a igualdade de tratamento, dentre outros. O processo, desse modo, é um meio para a efetivação de valores constitucionais, sendo que a atividade jurisdicional que dele resulta deve ser, via de regra, célere, eficaz, justa e igualitária.

Como um dos caminhos para alcançar tal desiderato, o novo CPC priorizou a isonomia nas decisões de casos similares, prestigiando os chamados "precedentes vinculantes" dos Tribunais, com vistas a alcançar uma maior igualdade nos resultados de processos que tratam da mesma questão de fato e de direito, com o objetivo de resguardar a segurança jurídica.

Isto porque a constante modificação da jurisprudência dos Tribunais, sem motivos justificáveis, acaba sendo fator de violação à segurança jurídica, pois impede a adoção de comportamentos padronizados por parte dos jurisdicionados, que não conseguem predisser qual será o resultado útil de um processo. Além disso, ainda há o fator isonômico, porquanto decisões conflitantes provenientes do mesmo órgão jurisdicional (considerando a unidade do Poder Judiciário) ferem a igualdade das partes no espectro do resultado do processo.

Há um sem-número de comentários favoráveis ou contrários à adoção dos precedentes judiciais vinculantes no Brasil. Há, inclusive, muitas críticas à utilização dessa terminologia. Apesar das importantes opiniões sobre a questão, o fato é que o novo Código de Processo Civil vige e adotou o termo "precedente". A problemática é merecedora de um longo tratado a respeito, o que não é o objetivo desse humilde estudo.

Pretende-se, apenas, demonstrar que o funcionamento e aplicação das normas 
referentes à força vinculante dos precedentes no novo diploma processual dependem de uma adequada aplicação da dialética de respeito aos precedentes própria de países que adotam a common law e a doutrina do stare decisis, posto que seu manejo, da forma como vem sendo feito, acaba por trazer uma série de tensões e divergências.

Assim sendo, o artigo procura demonstrar que a racionalidade dos precedentes não está somente na vinculação hierárquica dos precedentes dos tribunais superiores em relação aos órgãos julgadores inferiores, mas sim na valorização do conteúdo do precedente e no tratamento idêntico entre casos semelhantes.

O exame realizado objetiva analisar que a decisão que adota o precedente deve evidenciar a similitude das questões fáticas e de direito do paradigma com o caso sub judice, cotejando o caso concreto. Destarte, o presente estudo, de forma sucinta, almeja tecer reflexões sobre a aplicação e a flexibilização dos precedentes, que se fazem necessárias para que o novo Código de Processo Civil e a vinculação aos precedentes atinjam o desígnio de preservação da segurança jurídica e da igualdade.

No aspecto metodológico, é utilizado o método de orientação de conhecimento dedutivo. Quanto à natureza e ao objetivo, trata-se de uma pesquisa teórica, exploratória e explicativa, que busca o aprofundamento do conhecimento sobre o tema. Em relação à fonte de dados, pesquisa é bibliográfica, empregando-se legislação e doutrina, presentes em livros e artigos, impressos ou eletrônicos.

\section{OS PRECEDENTES E O NOVO CÓDIGO DE PROCESSO CIVIL}

Ao iniciar a análise de qualquer dos institutos e mecanismos do novo Código de Processo Civil (CPC), é possível observar inovações, aprimoramentos e atualizações ao sistema no compasso da evolução da ordem jurídica pátria, e tratar dos precedentes tem relação direta com esse aperfeiçoamento. Embora as decisões dos Tribunais já tivessem se apropriado de seu espaço no ordenamento jurídico, é com o novo CPC que as decisões judiciais assumem sua importância em defesa da igualdade e da segurança jurídica.

Antes de iniciar a análise da força das decisões judiciais, importante a ser fixado é o conceito de precedente e de jurisprudência, para com isso deixar elucidado que o que vincula as demais decisões é o precedente e não a mera jurisprudência do Tribunal. Quando conceitua 
jurisprudência, Santos (2012, p.145) afirma que o termo designa "a massa de decisões, normalmente em sentido constante, produzida por determinado órgão judicial” e, na sequência, conceitua precedente judicial como "uma decisão potencialmente relevante para influenciar no julgamento de outros casos no futuro".

Quantitativamente, jurisprudência consiste num conjunto de decisões em determinado sentido, em contrapartida pode a decisão precedente, ser uma única decisão proferida pelo Tribunal. Qualitativamente, a decisão emitida pelo acordão precedente, que será paradigma para outras decisões, é uma decisão com análise praticamente exaustiva dos fundamentos judiciais para aquele fato determinado, o que não é exigido para os processos que formam jurisprudência.

Informa Marinoni (2011, p. 216) que, para constituir um precedente, a decisão emanada do Poder Judiciário deverá enfrentar "todos os principais argumentos relacionados à questão de direito posta na moldura do caso concreto", o que pode ser feito em uma única decisão, ou necessitar de várias decisões para quedar-se concebido.

\footnotetext{
O juiz que considera o passado mostra respeito ao Poder de que faz parte e à confiança nele depositada pelo jurisdicionado. No entanto, se o magistrado é consciente de que a sua decisão poderá formar um precedente, o qual deverá ser respeitado pelos seus sucessores e interferirá sobre o comportamento das pessoas, a sua preocupação e responsabilidade pessoal certamente se intensificam. Quando se pensa em termos de precedente, a decisão de hoje não apenas considera o passado, mas também serve de guia para o futuro. (MARINONI, 2011, P. 109).
}

O CPC de 1973, em sua redação original, no Capítulo I, do Título IX, cuidando da uniformização da jurisprudência, trazia o art. 479 que mencionava a expressão "precedente" ao definir que "o julgamento, tomado pelo voto da maioria absoluta dos membros que integram o tribunal, será objeto de súmula e constituirá precedente na uniformização da jurisprudência" (BRASIL, 1973). O CPC de 1973 entrou em vigor e saiu do cenário nacional utilizando o termo "precedente" essa única vez, não havendo a inserção da expressão nas consequentes e constantes alterações do diploma processual.

Moreira (1974, p. 33) contextualiza a emissão da súmula e a constituição do precedente do art. 479, do antigo CPC, com os regimentos internos do Supremo Tribunal Federal (STF). Conforme informa o autor, a súmula de jurisprudência dominante foi inserida no regimento interno do STF em 1963, permanecendo no texto de seu novo regimento interno, publicado em 4 de setembro de 1970 (BRASIL, STF, 1970).

De acordo com o art. 98, do então novo regimento, "a jurisprudência firmada pelo 
Tribunal será compendiada na súmula do Supremo Tribunal Federal”, e consequentemente estabelece o art. $22, \S 1^{\circ}$, do mesmo decreto, que "poderá o relator arquivar ou negar seguimento a pedido ou recurso [...], quando contrariar a jurisprudência dominante do Tribunal (art. 98) ou for evidente a sua incompetência" (BRASIL, STF, 1970).

No entanto, embora possa o relator utilizar da súmula para impedir o seguimento de pedido ou recurso no STF, afirma Moreira (1974, p. 34) que "as proposições constantes da súmula não tem obrigatoriedade assimilável à da lei, não vinculam os outros tribunais do país, nem os juízos de primeiro grau", e esse foi o posicionamento interpretativo adotado na origem do CPC de 1973, havendo os que, inclusive, adotassem posicionamentos críticos quanto ao instituto.

4. a Súmula não constitui regra de observância obrigatória, como se fora texto de lei. Representa, apenas "precedente na uniformização da jurisprudência”. O intérprete, o julgador, está livre para analisar seu conteúdo, aceitando, ou não, a tese que nele se contém. Entender de outro modo é admitir a cristalização do direito e negar sua dinâmica renovadora. Será a conversão das Súmulas em superleis. (PAULA, 1998, p. 1.933)

No entanto, com as reformas sofridas pelo CPC de 1973, houve toda uma mudança de paradigma e aos poucos as decisões dos Tribunais Superiores passaram a se tornar vinculantes, servindo de base para as decisões provir. A primeira grande reforma, com a finalidade de desafogar o Poder Judiciário e de efetivar a prestação da tutela jurisdicional, foi inserida no CPC de 1973 pela Lei 9.756/1998, que deu nova redação ao art. 557, instituindo que "o relator negará seguimento a recurso [...] em confronto com súmula dominante do respectivo Tribunal, do Supremo Tribunal Federal, ou de Tribunal Superior" (BRASIL, 1998).

Foi com esse artigo que o CPC de 1973 passou a admitir a eficácia extramuros das súmulas dos Tribunais. Para Bermudes (2010, p. 194), “torna-se visível, no art. 557 e seus parágrafos, a preocupação com a celeridade processual e o empenho de desafogar os tribunais, à custa de uma eficácia normativa da jurisprudência”. Houve uma atribuição de força normativa às decisões dos Tribunais, o que não poderia ser diferente.

A Emenda Constitucional n. 45 de 2004, chamada de "reforma do Judiciário", criou, então, um novo instituto chamado "súmula vinculante", inserindo o art. 103-A na Constituição Federal de 1988, sendo posteriormente regulamentado pela Lei n. 11.417, de 19 de dezembro de 2006. Os enunciados da súmula da jurisprudência dominante com eficácia vinculante são conceituados como proposições aprovadas ou revisadas, de ofício ou por 
iniciativa de legitimado ativo determinado na lei, por dois terços dos membros do Supremo Tribunal Federal, quanto à interpretação, à validade e à eficácia de normas determinadas. Possuem efeito vinculante em relação aos demais órgãos do Poder Judiciário e à Administração Pública direta ou indireta, nas esferas federal, estadual e municipal, sob pena do uso de reclamação (TUCCI, 2004, p.147).

Na sequência, outros institutos foram inseridos, em 2006, no CPC de 1973, nessa mesma toada de fortalecer os tribunais e inclusive os próprios juízes de $1^{\circ}$ grau. Foi incorporado ao CPC o mecanismo da súmula impeditiva de recurso, no art. 518, §1 , permitindo ao juiz não receber recurso de apelação quando a sentença for conforme súmula do Superior Tribunal de Justiça (STJ) e do STF; o mecanismo da força vinculante das decisões proferidas com base no art. 543-B, que estabeleceu os recursos extraordinários repetitivos, quando da interposição de recursos com fundamento em idêntica controvérsia, cuja decisão serviria de base para que os Tribunais, Turma de uniformização e as Turmas recursais decidissem os processos que estão suspensos a seus cuidados; e ainda a hipótese do art. 285-A, que disponibiliza ao juiz de $1^{\circ}$ grau a possibilidade de sentenciar desde logo, inclusive independentemente da citação do réu, se já tiver sido proferida decisão de total improcedência no juízo.

Houve ainda, em 2008, a inclusão do art. 543-C ao CPC de 1973, instituindo o mecanismo do julgamento de recursos repetitivos, ou julgamento por amostragem (WAMBIER; TALAMINI, 2015, p. 834), com a finalidade eminente de economia processual, "represando-se provisoriamente no tribunal de origem, até que seja julgada única e definitivamente a questão repetitiva" (WAMBIER; TALAMINI, 2015, p. 834). A decisão do Tribunal Superior é usada para que os Tribunais inferiores julguem os demais recursos suspensos sobre a sua responsabilidade.

Observa-se que houve todo um fortalecimento das decisões judiciais, principalmente com a inserção, em 1998, da reclamação constitucional, em caso de desrespeito às decisões vinculantes e erga omnes, proferidas em processo de controle de constitucionalidade.

Nesse momento, pontua-se que é sabido que nas ordens jurídicas mundiais, em decorrência de circunstâncias histórias, políticas, sociais e culturais, há a tradição jurídica baseada no sistema da civil law, dominante na ordem jurídica pátria, que nasce baseada na mera declaração judicial da lei, na superioridade dessa e na separação absoluta entre em Poderes; e em contraposição, há o sistema da common law, no qual o direito seria delineado pelos tribunais. 
Porém, com a evolução jurídica, hoje não há mais uma separação marcante entre os dois sistemas, mas sim que as ordens jurídicas respeitam um sistema predominantemente, porém há mescla de institutos do outro sistema, principalmente fundamentado na efetividade, na segurança jurídica e na igualdade.

\begin{abstract}
Existe um recíproca aproximação entre as tradições de civil law e de common law no mundo contemporâneo. De um lado, a tradição do common law cada vez mais trabalha com o direito legislado, fenômeno que já leu a doutrina a identificar statutorification do common law e se perguntar a respeito de qual o lugar do common law em uma época em que cada vez mais vige o statutory law. De outro lado, a tradição de civil law cada vez mais se preocupa em assegurar a vigência do princípio da liberdade e da igualdade de todos perante o direito trabalhando com uma noção dinâmica do princípio da segurança jurídica, o que postula a necessidade de acompanharmos não só o trabalho do legislador, mas também as decisões dos tribunais, em especial das Cortes Supremas, como expressão do direito vigente. (MITIDIERO, 2015, p. 334)
\end{abstract}

Segundo Souza (2011, p. 310-312) foi o constitucionalismo, com a superação da ideia do Judiciário como mera bouche de la loi, que acabou por afastar a concepção dicotômica dos dois sistemas em termos absolutos. E essa aproximação influenciou, e muito, o novo Código de Processo Civil, que não apenas trata de "precedentes" expressamente, como institui vários mecanismos de respeito às decisões judiciais. Segundo a exposição de motivos do novo CPC “essa é a função e a razão de ser dos tribunais superiores: proferir decisões que moldem o ordenamento jurídico, objetivamente considerado" (BRASIL, 2010, p. 17).

É importante que se diga que o respeito ao precedente envolve a psicologia ou a tradição jurídica que permeia o sistema judicial de common law, mas não se trata de componente exclusivo deste, inadequado ao civil law. A França, a Hungria e a Espanha são exemplos de países de tradição do civil law que acolheram, no todo ou em parte, a ideia de precedentes vinculantes (DAVID, 2002, p. 491).

Instituir mecanismos de respeito a decisões judiciais superiores, ou até mesmo de suas próprias decisões judiciais, fortalece o Poder e apazigua os ânimos sociais, pois não é possível aceitar que situações idênticas possam ser tratadas de maneira distinta pelo Poder Judiciário, pois, como bem informa a exposição de motivos, "esse fenômeno fragmenta o sistema, gera intranquilidade e, por vezes, verdadeira perplexidade na sociedade" (BRASIL, 2010, p. 17).

O juiz que contraria a sua própria decisão, sem a devida justificativa, está muito longe do exercício de qualquer liberdade, estando muito mais perto da prática de um ato de insanidade. Enquanto isso, o juiz que contraria a posição do tribunal, ciente de que a este cabe a última palavra, pratica ato que, ao atentar contra a lógica do sistema, significa desprezo ao Poder Judiciário e desconsideração para com os usuários do serviço jurisdicional. (MARINONI, 2011, p. 65) 
$\mathrm{O}$ novo $\mathrm{CPC}$, nessa toada de respeito aos precedentes e às decisões judiciais, revigora, consolida, os princípios da segurança jurídica e da igualdade, como bem demonstra seu art. $7^{\circ}$, ao dispor que "é assegurada às partes paridade de tratamento em relação ao exercício de direitos [...]" (BRASIL, 2015). Não há motivos, segundo o novo CPC, de casos idênticos serem tratados de forma diferente pelos órgãos do Poder Judiciário.

O novel diploma processual, Lei 13.105/2015, em sua redação atual, dada pela Lei 13.256/2016, ocupa-se especificamente da palavra "precedente" basicamente em quatro momentos. Nos dois primeiros momentos, nos incisos V e VI, do art. 489, o CPC exige do magistrado que, ao fundamentar uma decisão baseada em precedentes ou mesmo em enunciados de súmulas, deverá demonstrar que o caso sob julgado é idêntico à causa paradigma. Há necessidade que demonstre "as razões que tornam a regra adequada para resolver aquele caso concreto específico" (WAMBIER et.al, 2015, p.796).

Na sequência, o inciso VI do art. 489, exige que o magistrado, entendendo pela não aplicação do precedente ou da súmula, deverá, igualmente, demonstrar tal inaplicação, fazendo o necessário distinguishing, ou mesmo, o possível overruling. Segundo Marinoni, "o distinguishing é apenas a declaração de que o direito evidenciado no precedente não regula o caso sob julgamento" (2011, p. 329), já o overruling é a possibilidade de superação do entendimento: "é possível em situações especiais e, de regra, pode ser realizada pelo tribunal que criou o precedente ou por corte superior” (WAMBIER et.al. 2012, p. 569).

Assim, não será considerada fundamentada qualquer decisão judicial, seja ela interlocutória, sentença ou acórdão, que se limitar a invocar precedente ou enunciado de súmula, sem identificar seus fundamentos determinantes nem demonstrar o ajuste do caso sob julgamento; ou que deixar de seguir enunciado de súmula, jurisprudência ou precedente invocado pela parte, sem demonstrar a existência de distinção no caso em julgamento ou a superação do entendimento (BRASIL, 2015).

Ocorre que a fundamentação, até por ordem do art. 93, IX, da Constituição Federal de 1988, é um dos elementos essenciais da decisão e, conforme se defere do inciso II do caput e do $\S 1^{\circ}$ do art. 489 do CPC, se é considerada não fundamentada, por ser esta inexistente ou insuficiente, a decisão será passível de nulidade (ASSIS, 2015, p. 946).

O art. 926, norma cujos destinatários são os Tribunais, traz a determinação de que estes devem uniformizar sua jurisprudência e mantê-la estável, íntegra e coerente, deixando clara a intenção do novo CPC de atender a valores constitucionais, já que a coesão entre 
decisões judiciais não é só basilar à autoridade e à confiabilidade do Poder Judiciário, como é indispensável ao Estado Democrático de Direito.

O $\S 2^{\circ}$ do art. 926, na sequência, estabelece que os Tribunais, ao editarem súmula, devem se ater ao plano fático dos precedentes que motivaram a sua publicação. O novo diploma processual, assim, de maneira acertada, deixa evidente que precedente não é súmula, e súmula não é precedente. Súmulas são meros enunciados, e não uma decisão que se qualifica como precedente (MARINONI, 2011, p. 216).

O precedente obrigatório, embora se relacione com pessoas que não participaram do
processo, tem a sua legitimidade condicionada a ter sido proferido em processo com
adequada participação dos litigantes em contraditório, os quais zelam para que a tese
jurídica não seja desfigurada. Assim, a preocupação, como parte, com os efeitos da
decisão, ou, mais precisamente, com a coisa julgada, curiosamente confere
legitimidade à eficácia do precedente obrigatório em relação aos terceiros.
(MARINONI, 2011, p. 217).

Em sentido contrário, as súmulas não possuem a mesma autoridade, eis que "simplesmente neutralizam as circunstâncias do caso ou dos casos que levaram a sua edição. As súmulas apenas se preocupam com a adequada delimitação de um enunciado jurídico" (MARINONI, 2011, p. 218).

Por conseguinte, não é possível, de acordo com o novo CPC, e até mesmo de acordo com o sistema anterior, editar verbete de súmula que se desgarre dos precedentes que justificaram sua edição. Porém, tal lógica nem sempre é levada em consideração no momento da edição de súmulas, nascendo muitas vezes textos sumulares que desgarram diretamente de seus precedentes, como, por exemplo, aconteceu com a Súmula n. 297, do STJ (BRASIL, 2004), que disciplina que “o Código de Defesa do Consumidor é aplicável às instituições financeiras", muito embora seus precedentes apenas se refiram à atividade bancária.

As súmulas devem estar estritamente relacionadas ao caso concreto discutido. Ainda que os Tribunais Superiores não analisem o aspecto fático das causas que lhe são enviadas, tal análise não é feita em abstrato, há sim uma situação fática como fundo da decisão. Emitir súmula não baseada no caso concreto discutido afronta todo o sistema constitucional e processual.

As súmulas, quando vistas como enunciados gerais e abstratos, fazem esquecer que sua origem está nos casos concretos, ou melhor, nos precedentes que a formaram. Nesse sentido, para saber se uma súmula é aplicável a outro caso, é imprescindível verificar o contexto dos precedentes que lhe deram origem, pois somente assim será possível constatar se 
as condições de fato e de direito que estiveram presentes no julgamento daqueles precedentes - os quais deram origem à súmula - estão realmente presentes no caso sub judice (MARINONI, 2011, p. 483).

E, por fim, a palavra "precedente" é mencionada no $\$ 5^{\circ}$ do art. 927 , ao estabelecer que "os tribunais darão publicidade a seus precedentes [...]" (BRASIL, 2015), com a finalidade precípua de que aos litigantes seja dada ciência das regras do jogo, pois ao retirarem o Poder Judiciário da sua inércia, devem fazê-lo sabendo as consequências que lhes aguardam. Não é aceitável que o Tribunal, ou mesmo o juiz de primeiro grau, mude seu posicionamento a seu "bel-prazer", sem fundamentar tal decisão.

\begin{abstract}
A vinculação das decisões dos órgãos jurisdicionais inferiores ao precedente emanado pelo Tribunal impacta de forma definitiva sobre as decisões a serem tomadas por esses órgãos. Em razão disso, a mudança de entendimento sedimentado não pode ocorrer de forma aleatória, ou ao bel-prazer do Tribunal. Com o poder vinculante da jurisprudência, a segurança jurídica ganha um novo parâmetro de avaliação; não se pode, pois, proceder a qualquer alteração de entendimento já pacificado sem ampla discussão e participação da sociedade, mesmo porque haverá a necessidade de direcionar de forma nova a situação envolvida (tanto é assim que se admite a participação de pessoas, órgãos e entidades no processo, bem como a realização de audiências públicas). (NERY JUNIOR; NERY, 2015, p. 1917)
\end{abstract}

Embora o novo CPC apenas mencione a palavra "precedente" nesses quatro dispositivos, o caput do art. 927 diz que os juízes e os tribunais observarão: i) as decisões do Supremo Tribunal Federal em controle concentrado de constitucionalidade; ii) os enunciados de súmula vinculante; iii) os acórdãos em incidente de assunção de competência ou de resolução de demandas repetitivas e em julgamento de recursos extraordinário e especial repetitivos; iv) os enunciados das súmulas do Supremo Tribunal Federal em matéria constitucional e do Superior Tribunal de Justiça em matéria infraconstitucional; v) a orientação do plenário ou do órgão especial aos quais estiverem vinculados.

Há, então, a previsão de mecanismos de respeito às decisões dos Tribunais, tal qual o incidente de resolução de demandas repetitivas (IRDR) e de assunção de competência (IAC), além do já conhecido julgamento do recurso extraordinário e especial repetitivo. Aos Tribunais de $2^{\circ}$ grau há a mesma responsabilidade de uniformização das decisões judiciais, pois a jurisprudência dispersa não é só de responsabilidade dos Tribunais Superiores, mas de todos os órgãos que formam o Poder Judiciário.

Por fim, há de se consignar que a Lei 13.256, de 04 de fevereiro de 2016, que alterou o Novo CPC, incluiu no art. 966 os parágrafos $5^{\circ}$ e $6^{\circ}$ para determinar que cabe ação rescisória, com fundamento no inciso $\mathrm{V}$ do caput (violação manifesta de norma jurídica), contra decisão baseada em enunciado de súmula ou acórdão proferido em julgamento de casos 
repetitivos que não tenha considerado a existência de distinção entre a questão discutida no processo e o padrão decisório que lhe deu fundamento. Nessa hipótese, caberá ao autor da rescisória, sob pena de inépcia, demonstrar, fundamentadamente, tratar-se de situação particularizada por hipótese fática distinta ou de questão jurídica não examinada, a impor outra solução jurídica.

Não há dúvida, de toda essa digressão, que o novo CPC fortaleceu as decisões dos Tribunais, fundamentando-se na igualdade e na segurança jurídica, como pilares dessa nova ordem jurídica processual. Não há base para que o devido processo legal não trate o jurisdicionado da mesma forma, quando envolvido na mesma controvérsia.

\section{REFLEXÕES PARA UMA APLICAÇÃO COM BASE NA RACIONALIDADE DOS PRECEDENTES}

Nos termos acima analisados, o novo CPC procurou prestigiar as decisões consolidadas dos Tribunais, visando a alcançar uma maior igualdade nos processos que tratam da mesma questão de fato e de direito, como forma de resguardar princípios constitucionais, como o da isonomia e da segurança jurídica, bem como da unidade da jurisdição.

A ausência de uma cultura jurídica com base nos precedentes faz surgir inúmeros questionamentos e críticas que colocam em cheque os objetivos idealizados pelo novo diploma processual. Apesar das importantes opiniões sobre a questão, o fato é que as normas do novo Código de Processo Civil estão vigendo. Não se pretende, tendo em vista os objetivos delimitados para o presente estudo, analisar a problemática que gira em torno da função criativa do Direito. Pretende-se, apenas, demonstrar que é fundamental que algumas técnicas de aplicação e de flexibilização dos precedentes, desenvolvidas ao longo dos anos pelos países que adotam o sistema da common law e a doutrina do stare decisis, sejam estudadas, absorvidas e adaptadas ao sistema jurídico brasileiro.

Assim, o funcionamento e aplicação das normas referentes à força vinculante dos precedentes do novo CPC dependem de uma adequada atenção à dialética de respeito aos precedentes, posto que seu manejo, da forma como vem sendo feito, coloca em risco seu desiderato. Nesse sentido, é imprescindível se notar que a decisão que adota o precedente não pode fugir do contexto do caso símile decidido pelo Tribunal. Não basta a mera menção à 
súmula ou ao acórdão. A decisão que adota o precedente como paradigma deve ser suficientemente fundamentada a demonstrar a similitude das questões fáticas e de direito do precedente com o caso sub judice.

Os precedentes não se prestam à produção de teses abstratas e gerais por Cortes de Vértice. O dever de coerência e de integridade não significa a incorporação irrefletida de uma "teoria dos precedentes", pois, caso assim seja, haverá “[...] juiz (e desembargadores) bocados-precedentes (ou teses). Ou seja, o boca da lei troca de nome e função" (STRECK, 2016).

No sistema dos precedentes, adotado nos países que seguem a cultura da common law, baseado na doutrina do stare decisis, os fatos e as considerações jurídicas em torno dos fatos - cuja análise é essencial para identificar a similaridade entre os casos - possuem centralidade na fundamentação da decisão. Isto porque, a racionalidade e a vinculatividade dos precedentes não está apenas no vínculo hierárquico ou na decisão em si, mas antes nas razões de decidir, na chamada ratio decidendi (SARTORI, 2014, p. 150).

Por conseguinte, para que os objetivos do novo diploma processual possam se concretizar, de modo a uniformizar a jurisprudência, no sentido de dar mais coerência e previsibilidade às decisões judiciais, a cultura jurídica do Brasil está a exigir uma forçosa reflexão sobre a racionalidade aplicada aos precedentes nos países da common law.

A expressão "stare decisis" provém da abreviação da máxima latina "stare decisis et non quieta movere", que significa "mantenha-se a decisão e não se disturbe o que foi decidido" (RE, 1994, p. 282). No sistema do common law, onde o Direito é enunciado e desenvolvido segundo decisões judiciais, a doutrina do stare decisis é absolutamente essencial, pois, segundo esta doutrina, um princípio de direito deduzido através de uma decisão judicial poderá ser considerado e aplicado na solução de um caso semelhante no futuro.

"Na essência, esta orientação indica a probabilidade de que uma causa idêntica ou assemelhada que venha a surgir no futuro seja decidida da mesma maneira” (RE, 1994, p. 282). Logo, a regra do stare decisis inspira-se em razões de isonomia, previsibilidade, estabilidade e segurança jurídica, na medida em que casos iguais devem ser decididos da mesma maneira.

Contudo, adverte Streck e Abboud (2014, p. 40-41), o stare decisis é mais do que a aplicação da regra de solução análoga para casos iguais, pois a máxima "treat like cases alike” já era aplicada anteriormente pelas cortes dos países que adotam a common law. O stare decisis veio depois, com a sistemática alusão aos casos anteriores desenvolvendo-se 
continuamente a diferenciação entre o que seria a holding (a vincular casos futuros) e o dictum (razões utilizadas que não são fundamentais para o deslinde do caso), que não possui efeito vinculante.

A palavra "precedente" teria sido utilizada pela primeira vez em 1557, e significa a decisão de um Tribunal com aptidão para ser reproduzida pelos órgãos inferiores na resolução de casos análogos-similares. A doutrina do stare decisis, embora tenha se originado da doutrina dos precedentes, com esta não se confunde, porquanto aquela pretende estabelecer, com maior clareza, a diferença entre holding e dictum (STRECK; ABBOUD, 2014, p. 43-45).

Os precedentes, ao contrário do que se pensa, não são aplicados de forma automática. Embora comumente se faça referência à eficácia obrigatória do precedente, deve-se entender que o que tem caráter obrigatório é a holding (ruling of a court), que é o princípio legal derivado de uma decisão judicial, é a parte da decisão judicial na qual a lei é especificamente aplicada aos fatos controvertidos. Ela é invocada quando as cortes usam o caso como precedente no caso subsequente (WEST'S ENCYCLOPEDIA OF AMERICAN LAW, 2008).

A holding de um caso é sua ratio decidendi, que, em uma primeira análise, poderia ser tida como a cognição utilizada para alcançar o resultado, com base nas questões arguidas pelas partes. É a regra jurídica utilizada pelo Judiciário para justificar a decisão (STRECK; ABBOUD, 2014, p. 46). A razão de decidir, apesar de estar localizada na fundamentação da decisão, com esta não se confunde, pois, na fundamentação também haverá questões incidentais, não fundamentais à decisão, são as chamadas obter dicta (ou dictum no singular); sendo que somente as razões de decidir terão força vinculante. Igualmente, a ratio decidendi não se confunde com o dispositivo da decisão (MARINONI, 2011, p. 222).

Tucci (2004, p. 175) diz que ratio decidendi pode ser tida como os fundamentos jurídicos que sustentam a decisão, a opção hermenêutica adotada na sentença, sem a qual a decisão não teria sido proferida como foi. Trata-se da tese jurídica suficiente para decidir o caso concreto (rule of law) sendo composta: a) pela indicação dos fatos relevantes da causa (statement of material facts); b) do raciocínio lógico-jurídico da decisão (legal reasoning), e; c) do juízo decisório (judgment).

Cada precedente terá, desse modo, uma ratio decidendi. Didaticamente, com Pierluigi Chiassoni, é possível elencar sete conceitos cunhados pela tradição sobre ratio decidendi: "é o critério decisional, ou seja, a regra que está subjacente à decisão; é o princípio de direito adotado para definir o conteúdo da demanda; é a premissa ou a passagem lógica que se revela necessária para se alcançar a decisão do 
caso; é a regra ou princípio que constitui a condição necessária ou suficiente; é o princípio de direito contido na decisão judicial e que é suficiente para decidir o caso concreto; é a argumentação explícita ou implícita necessária ou suficiente para definir o caso e, por último, é a relação entre resolução (motivada) do caso e o próprio caso, ou seja, o fato e as questões jurídicas inerentes". (STRECK; ABBOUD, 2014, p. 46).

Por sua vez, o obter dictum, que não possui força vinculante, corresponde ao enunciado, interpretação jurídica ou argumentação, presente expressamente no conteúdo da decisão, mas cujo conteúdo mostra-se irrelevante ao deslinde da demanda (STRECK; ABBOUD, 2014, p. 47).

Observa-se, de tal modo, que a ratio decidendi, tida como a norma geral constante da decisão, deve ser interpretada à luz do caso concreto. Isso porque ela não é uma regra jurídica que pode ser considerada isoladamente, “[...] uma vez que a ratio decidendi deve, obrigatoriamente, ser analisada em correspondência com a questão fático-jurídica (caso concreto) que ela solucionou" (STRECK; ABBOUD, 2014, p. 46). Dessa forma, a fundamentação da decisão sucessiva deverá conter expressa alusão à ratio decidendi do precedente, cotejando o caso concreto, não bastando a mera alusão à tese jurídica anunciada.

Portanto, inexiste aplicação mecânica ou subsuntiva na solução dos casos mediante a utilização do precedente judicial. Isto porque não existe uma prévia e pronta regra jurídica apta a solucionar por efeito cascata diversos casos futuros. Pelo contrário, a própria regra jurídica (precedente) é fruto de intenso debate e atividade interpretativa, e, após localizado, passa-se a verificar se na circunstância do caso concreto que ele virá solucionar é possível utilizá-lo sem que ocorram graves distorções, porque se elas ficarem caracterizadas, o precedente deverá ser afastado. (STRECK; ABBOUD, 2014, p. 49).

Esse enquadramento, obviamente, não é simples e requer racionalidade jurídica, portanto, sempre dependerá de uma argumentação adequada das questões de direito, apresentada por quem invoca o precedente e, no mesmo sentido, da aproximação dos fatos do precedente e dos fatos sob julgamento (SARTORI; SCHNEIDER, 2013, p. 223-224).

$\mathrm{O}$ uso do precedente justifica-se do ponto de vista do discurso, porque o campo do discursivamente possível não poderia ser preenchido com decisões mutáveis e incompatíveis entre si; o uso do precedente significa aplicar a norma e, nesse sentido, é mais uma extensão do princípio da universalidade. Por outro lado, a obrigação de seguir um precedente não é absoluta, mas quem se afasta do precedente assume a carga da argumentação (ATIENZA, 2006, p. 178).

Logo, o precedente não engessa o sistema jurídico, ele o dinamiza, na medida em que a interpretação do precedente deve levar em conta a “[...] totalidade do ordenamento jurídico e 
toda a valoração e a fundamentação que o embasaram, assim, sempre que ele for a base de uma nova decisão, seu conteúdo é passível de uma ajuste jurisprudencial” (STRECK; ABBOUD, 2014, p. 50).

Não se deve aceitar cegamente o precedente. Caberá ao aplicador do direito fazer o distinguishing que é a técnica que permite que se distinga o caso presente de outros precedentes já julgados, de modo a afastar o caso sub judice da força vinculante dos precedentes. Para aplicar a ratio decidendi é necessário comparar o caso de que ela provém com o caso sob julgamento. Destarte, a técnica do distinguishing exige, como antecedente lógico, a identificação da ratio decidendi, ou seja, a identificação dos fatos que foram tomados em consideração no raciocínio judicial como relevantes à decisão (MARINONI, 2011, p. 327).

Para se afastar dessa decisão, o magistrado deve, obrigatoriamente, proceder à exaustiva fundamentação, a fim de evidenciar que, para aquele caso concreto, não deve ser mantida a aplicação do precedente, lançando mão do distinguishing (STRECK; ABBOUD, 2014, p. 39). Nessa linha, fala-se em distinguishing quando houver distinção entre o caso concreto em julgamento e o paradigma, seja porque não há coincidência entre os fatos fundamentais discutidos e aqueles que serviram de base à ratio decidendi constante do precedente, seja porque, a despeito de existir uma aproximação entre eles, alguma peculiaridade no caso em julgamento afasta a aplicação do precedente.

Adverte, nesse sentido, Schauer (1987, p. 599) para o perigo do uso do precedente de maneira abrangente, pois aquele que julga não pode olvidar de analisar os fatos particularizados de um caso por haver decisão anterior que aparentemente possa ser um precedente. A vinculação a um precedente visando solucionar um caso presente pode acabar gerando uma decisão não-ideal para aquele impasse, se não levados em consideração seus fatos particularizados.

Ensina Taruffo (2007, p. 13-14) que o precedente fornece uma regra que pode ser aplicada como critério de decisão no caso sucessivo em função da identidade ou, como acontece de regra, da analogia entre os fatos do primeiro caso e os fatos do segundo caso. Dessa forma, a analogia das duas fattispecie concretas não é determinada in re ipsa, mas sim afirmada ou excluída pelo juiz do caso sucessivo conforme se considere prevalentes os elementos de identidade ou os elementos de diferença entre os fatos dos dois casos. É, portanto, o juiz do caso sucessivo que estabelece se existe ou não existe o precedente. Assim, 
a estrutura fundamental do raciocínio que sustenta e aplica o precedente ao caso sucessivo é fundada na análise dos fatos. Se esta análise justifica a aplicação ao segundo caso da ratio decidendi aplicada ao primeiro, o precedente é eficaz e pode determinar a decisão do segundo caso.

O raciocínio feito pelo tribunal que decidiu o precedente não pode ser ignorado. E a seleção dos fundamentos de fato e de direito, considerados necessários para a criação da regra, é de vital relevância. Vale lembrar que decisões judiciais apreciam situações concretas (com exceção das ações de controle (in) constitucionalidade abstratas), enquanto a lei procura regular situações abstratas. Significa dizer que o aplicador do direito, seja o advogado ou o juiz, jamais poderá ater-se à leitura da ementa de acórdão ou enunciado da súmula, como se regra geral e abstrata fosse, sob pena de violação à cláusula da separação dos poderes, e aos princípios constitucionais da legalidade e da inafastabilidade da tutela jurisdicional (SARTORI; SCHNEIDER, 2013, p. 224).

Ementa e verbete não são normas gerais e abstratas, como a lei, logo, não podem ser aplicadas por subsunção. Precedentes não se prestam à produção de teses abstratas e gerais. Por conseguinte, a exposição da análise efetuada para aplicação do precedente deve vir descrita na fundamentação, salientando-se a similitude entre os fatos essenciais, identificandose a ratio decidendi. Pois, somente através da demonstração efetiva da apreciação judicial será minimizada a possibilidade de vulneração dos princípios constitucionais supracitados.

A aplicação generalizada e automática de um precedente, como se dispositivo de lei fosse, viola, de uma só vez, todos esses princípios e garantias, seja porque confere verdadeiros poderes legislativos ao Poder Judiciário, seja porque irão impor verdadeiras obrigações positivas ou negativas aos particulares sem assento em lei (ainda que indiretamente), afastando o titular do direito do acesso à jurisdição.

Há de se destacar, ainda, o overruling que é a técnica de revogação do precedente. Um precedente está em condições de ser revogado quando deixa de corresponder aos padrões de congruência social e de consistência sistêmica e, ao mesmo tempo, os valores que sustentam a estabilidade - basicamente os da isonomia, da confiança justificada e da vedação da surpresa injusta - mais fundamentam a sua revogação do que sua preservação (MARINONI, 2011, p. 390-391)

Com efeito, as cortes superiores podem então substituir - overruled - determinado precedente por considerá-lo ultrapassado ou, ainda, errado (per incuriam ou per ignorantia legis). A decisão que acolhe nova orientação incumbe-se de revogar expressamente a ratio decidendi anterior (express overruling). Nesse caso, o antigo paradigma hermenêutico perde todo o seu valor. (TUCCI, 2012, p. 108). 
A vinculação aos precedentes, longe de ser fixa e definitiva, com as possibilidades do distinguishing e do overruling, “[...] traduz antes o sábio dúctil equilíbrio, praticamente conseguido, entre estabilidade e a continuidade jurídicas, por um lado, e a abertura e a liberdade jurisdicionais, por outro lado [...]” (NEVES, 1983, p. 669).

\begin{abstract}
Portanto, é despropositado pensar que o respeito aos precedentes pode gerar injustiça, em virtude da impossibilidade da consideração das peculiaridades de uma dada posição ou situação jurídica. Na realidade, num sistema que respeita precedentes, a nenhum juiz é dada a possibilidade de aplicá-los a casos que têm particularidades que os tornam distintos, a repelir o tratamento igualitário ou uniforme. Não há distinção entre mal aplicar precedentes e mal aplicar normas legais. Ora, a igualdade formal diante da lei pode coexistir com uma forte desigualdade de tratamento. Enfim, aplicar a mesma lei a situações desiguais é o mesmo que aplicar um mesmo precedente a casos substancialmente distintos. (MARINONI, 2011, p. 196-197).
\end{abstract}

Ultima-se que, muito embora seja comum ouvir falar que um sistema de precedentes obrigatórios impedirá o desenvolvimento do direito, tal afirmação não deve ser levada em conta. Não só o distinguishing, como também o overruling, dentre outros métodos aqui não analisados, são peças vitais a qualquer sistema de precedentes obrigatórios, de modo que é um equívoco pensar em uma aplicação irrefletida, automática e absoluta dos precedentes.

\title{
CONCLUSÃO
}

O novo Código de Processo Civil, conforme visto, seguiu a tendência de criar estímulos para que a jurisprudência se uniformize, à luz do que venham a decidir tribunais superiores e até de segundo grau, e se estabilize. O novo Código, assim, prestigia o princípio constitucional da isonomia e da segurança jurídica, que se hospedam nas dobras do Estado Democrático de Direito, visando a proteger e a preservar as justas expectativas das pessoas.

O magistrado, ao proferir sua decisão, não pode se esquecer de que é membro de um órgão, e que exerce seu ofício como membro uma instituição una, o Judiciário. Assim, deve ter coerência as suas deliberações, de modo a garantir a isonomia de tratamento também em relação às decisões judiciais. Nesse diapasão, a força obrigatória dos precedentes é ferramenta indispensável na busca por previsibilidade, promoção da equidade e para a concepção do Judiciário como autoridade de voz una e harmônica.

Contudo, esse dever de coerência e de integridade não significa a incorporação irrefletida da doutrina dos precedentes. O panorama da crescente força vinculante da 
jurisprudência no direito brasileiro impõe uma reflexão sobre o valor do precedente e o perigo de sua generalização. Nesse sentido, o presente estudo procurou refletir sobre a questão dos precedentes vinculantes para demostrar que estes não se prestam à produção de teses abstratas e gerais.

Como visto, a cultura jurídica que envolve a força vinculante dos precedentes não está somente na vinculação hierárquica entre tribunais superiores e inferiores, mas sim na valorização do tratamento idêntico entre casos semelhantes, na valorização do conteúdo do precedente.

Por tal razão, a aplicação de um precedente deve se pautar por parâmetros próprios e específicos, diversos daqueles que informam a aplicação do direito legislado. O precedente não é uma norma abstrata e genérica feita pro futuro, mas sim uma regra intimamente ligada ao caso concreto, às questões de fato e de direito que lhe deram origem, razão pela qual a identificação e a assimilação de sua ratio decidendi, como já abordado, são imprescindíveis.

Vale lembrar, mais uma vez, que decisões judiciais apreciam situações concretas, enquanto a lei procura regular situações abstratas. Significa dizer que o aplicador do direito, seja o advogado ou o magistrado, jamais poderá ater-se à leitura da ementa do acórdão, do enunciado da súmula ou da tese fixada em orientação jurisprudencial, como se regra geral e abstrata fosse, sob pena de violação à cláusula da separação dos poderes e aos princípios constitucionais da legalidade e da inafastabilidade da tutela jurisdicional.

De tal modo, muito bem andou o novo CPC ao determinar que não será considerada fundamentada qualquer decisão judicial, seja ela interlocutória, sentença ou acórdão, que se limitar a invocar precedente ou enunciado de súmula. Deverá o magistrado, assim, fundamentar a utilização ou não de um determinado precedente cotejando o caso concreto decidido no precedente em relação ao caso sub judice, apresentando os fundamentos de fato e de direito que ligam (ou não) a sua decisão à ratio decidendi daquele precedente.

Também veio muito bem o novo diploma a exigir que a jurisprudência seja íntegra, estável e coerente, para que seja possível aos cidadãos ter fidedignas expectativas sobre o resultado de um processo, evitando-se decisões surpresas e o uso de recursos meramente protelatórios. O novo Código de Processo Civil igualmente converge com todas essas ideias quando estabelece que os Tribunais, ao editarem súmula, devem se ater ao plano fático dos precedentes que motivaram a sua publicação. O novo diploma processual, assim, de maneira acertada, deixa evidente que as súmulas não são precedentes e, por isso, não podem se desagarrar das decisões judiciais que justificaram sua edição. 
O maior desafio que a cultura jurídica brasileira terá que enfrentar para alcançar a almejada segurança jurídica e isonomia das decisões do Poder Judiciário será deixar de pensar nas decisões a partir de meras semelhanças conceituais.

Destarte, para que o novo Código de Processo Civil e a vinculação aos precedentes dos Tribunais atinjam os seus escopos, é fundamental que algumas técnicas de aplicação e de flexibilização dos precedentes, desenvolvidas ao longo dos anos pelos países que adotam o sistema da common law e a doutrina do stare decisis, sejam estudadas, absorvidas e adaptadas ao sistema jurídico brasileiro. Pois, somente assim, o processo será um meio para a efetivação de valores constitucionais, garantindo como resultado uma atividade jurisdicional célere, eficaz, justa e igualitária.

\section{REFERÊNCIAS BIBLIOGRÁFICAS}

ASSIS, Araken de. Processo Civil Brasileiro. Parte Especial. Procedimento Comum: da demanda à coisa julgada. 1 ed. em e-book baseada na 1 ed. impressa. São Paulo: Revista dos Tribunais, 2015, v. 3.

ATIENZA, Manuel. As Razões do Direito: Teorias da Argumentação Jurídica. Tradução de Maria Cristina Guimarães Cupertino. 3 ed. São Paulo: Landy, 2006.

BERMUDES, Sergio. A Reforma do Código de Processo Civil. 3. ed. São Paulo: Saraiva, 2010.

BRASIL. Supremo Tribunal Federal. Regimento Interno do Supremo Tribunal Federal. Diário da Justiça, 04 set. 1970. Disponível em: < http://www.stf.jus.br/arquivo/cms/bibliotecaConsultaProdutoBibliotecaRI/anexo/RegimentoIn terno1970Original.pdf>. Acesso em: 27 ago. 2016.

Lei 5.869, de 01 de janeiro de 1973. Institui o Código de Processo Civil. Diário Oficial da União, Brasília, 17 jan. 1973, republicado em 27 jul. 2006. Disponível em: <http://www.planalto.gov.br/ccivil_03/leis/L5869.htm>. Acesso em: 05 set. 2016.

Lei 9.756, de 17 de dezembro de 1998. Dispõe sobre o processamento de recursos no âmbito dos tribunais. Diário Oficial da União, Brasília, 18 dez. 1998, retificado em 05 jan. 1999. Disponível em: <http://www.planalto.gov.br/ccivil_03/leis/L9756.htm>. Acesso em: 05 set. 2016.

\footnotetext{
. Superior Tribunal de Justiça. Súmula n. 297. Diário de Justiça, Brasília, 09 set. 2004, p. 149 . Disponível em: < http://www.stj.jus.br/SCON/sumulas/doc.jsp?livre=\%40docn \&processo=297\&\&b=SUMU\& $\mathrm{p}=$ true $\& \mathrm{t}=\& \mathrm{l}=10 \& \mathrm{i}=1>$. Acesso em: 07 set. 2016.
} 
Congresso Nacional. Senado Federal. Código de Processo Civil: anteprojeto. Comissão de Juristas Responsável pela Elaboração de Anteprojeto de Código de Processo Civil. Brasília: Senado Federal, Presidência, 2010. Disponível em: <http://www.senado.gov.br/senado/novocpc/pdf/anteprojeto.pdf>. Acesso em: 31 ago. 2016.

. Lei 13.105, de 16 de março de 2015. Institui o Código de Processo Civil. Diário Oficial da União, Brasília, 17 mar. 2015. Disponível em: <http://www.planalto.gov.br/CCIVIL_03/_Ato2015-2018/2015/Lei/L13105.htm>. Acesso em: 05 set. 2016.

CAMARGO, Luiz Henrique Volpe. A força dos precedentes no moderno processo civil brasileiro. In: WAMBIER, Teresa Arruda Alvim (Coord.) et al. Direito Jurisprudencial. São Paulo: Revista dos Tribunais, 2012, p. 553-674.

DAVID, René. Os Grandes Sistemas do Direito Contemporâneo. Tradução de Hermínio A. Carvalho. São Paulo: Martins Fontes, 2002.

HOLDING. In: West's Encyclopedia of American Law, edition 2, 2008. Disponível em: <http://legal-dictionary.thefreedictionary.com/holding>. Acesso em: 24 set. 2016.

MARINONI, Luiz Guilherme. Precedentes Obrigatórios. 2 ed. São Paulo: Revista dos Tribunais, 2011.

MITIDIERO, Daniel. Precedentes, Jurisprudência e Súmulas no Novo Código de Processo Civil Brasileiro. Revista de Processo, São Paulo, v. 245, ano 40, jul.2015.

MOREIRA, José Carlos Barbosa Moreira. Comentários ao Código de Processo Civil: art. 476 a 565. Rio de Janeiro: Forense, 1974.

PAULA, Alexandre de. Código de Processo Civil Anotado: do processo de conhecimento, art. 270 a 565. São Paulo: Revista dos Tribunais, 1998.

NERY JUNIOR, Nelson; NERY, Rosa Maria de Andrade. Comentários ao Código de Processo Civil. São Paulo: Revista dos Tribunais, 2015, e-book.

NEVES, Antonio Castanheira. O Instituto dos Assentos e a Função Jurídica dos Supremos Tribunais. Coimbra: Coimbra, 1983.

RE, Edward D. Stare Decisis. Tradução de Ellen Gracie Northfleet. Revista de Informação Legislativa, Brasília, n. 122, maio/jul. 1994, p. 281-287. Disponível em: < http://www2.senado.leg.br/bdsf/bitstream/handle/id/176188/000485611.pdf?sequence=3 .

Acesso em: 07 ago. 2016.

SANTOS, Evaristo Aragão. Em torno do conceito e da formação do precedente judicial. In: WAMBIER, Teresa Arruda Alvim (Coord.) et al. Direito Jurisprudencial. São Paulo: Revista dos Tribunais, 2012, p. 133-201.

SARTORI, Ellen Carina Mattias; SCHNEIDER, Caroline. A "súmula impeditiva de recursos" 
e a "era" dos precedentes judiciais. In: XXII Congresso Nacional CONPEDI/UNINOVE, Processo e Jurisdição II, 2013, São Paulo, p. 212-236. Anais Eletrônicos. Florianópolis/SãoPaulo: $\quad$ Funjab, 2013. Disponível em: <http://www.publicadireito.com.br/artigos/?cod=99ef8a644d84701c>. Acesso em: 07 set. 2016.

Da súmula vinculante e da necessidade de uma cultura de respeito aos precedentes no Brasil. In: SIQUEIRA, Dirceu Pereira; OLIVEIRA, Flávio Luis (Org.). Acesso à justiça e concretização de direitos. Birigui: Boreal, 2014, p. 145-167.

SCHAUER, Frederick. Precedent. Stanford Law Review, Stanford, v. 39, n. 3, fev. 1987, p. 571-605.

SOUZA, Marcelo Alves Dias de. Do Precedente Judicial à Súmula Vinculante. Curitiba: Juruá, 2011.

STRECK, Lenio Luiz; ABBOUD, Georges. O que é isto - o precedente judicial e as súmulas vinculantes? 2 ed. rev. atual. Porto Alegre: Livraria do Advogado, 2014.

. Por que commonlistas brasileiros querem proibir juízes de interpretar? Revista Consultor Jurídico, São Paulo, Senso Incomum, 22 set. 2016. Disponível em: $<$ http://www.conjur.com.br/2016-set-22/senso-incomum-commonlistas-brasileiros-proibirjuizes-interpretar>. Acesso em: 22 set. 2016.

TARUFFO, Michelle. Precedente e Giurisprudenza. Napoli: Editoriale Scientifica SRL, 2007.

TUCCI, José Rogério Cruz e. Precedente Judicial como Fonte do Direito. São Paulo: Revista dos Tribunais, 2004.

WAMBIER, Luiz Rodrigues; TALAMINI, Eduardo. Curso Avançado de Processo Civil: teoria geral do processo e processo de conhecimento. 15 ed. São Paulo: Revista dos Tribunais, 2015 , v. 1 .

WAMBIER, Teresa Arruda Alvim (Coord.) et al. Direito Jurisprudencial. São Paulo: Revista dos Tribunais, 2012.

Primeiros Comentários ao Novo Código de Processo Civil: artigo por artigo. São Paulo: Revista dos Tribunais, 2015. 